\title{
Problems in the Use of Polycarbonate Diffusion Chambers for Syngeneic Pancreatic Islet Transplantation in Rats
}

\author{
N. A. Theodorou, Helena Vrbova, Margaret Tyhurst, and S. L. Howell \\ Departments of Surgery and Biochemistry, Charing Cross Hospital Medical School, Hammersmith, London, England
}

\begin{abstract}
Summary. Islets of Langerhans have been enclosed in polycarbonate diffusion chambers and transplanted intraperitoneally to syngeneic streptozotocin diabetic rats. Direct implantation of $1100-1400$ islets in these chambers failed to reverse diabetes during a period of 12 weeks, and viable islet tissue was not recoverable at the end of this period. Islets placed in chambers which had been implanted 3-12 weeks previously similarly failed to lower blood glucose of diabetic recipients, as a result of lack of survival of the islets. Insulin infusion into chambers previously implanted in vivo, $\mathrm{I}^{125}$ insulin diffusion studies in chambers recovered 6-8 weeks after implantation, and scanning electron microscopy of the recovered membranes all indicated that the pores were not totally occluded. The failure of islet transplantation via chambers in this simple syngeneic model has discouraging implications for their use as a means of avoiding allograft rejection.
\end{abstract}

Key words: Transplantation, islets of Langerhans, streptozotocin diabetes, diffusion chambers.

The reversal of streptozotocin-induced diabetes in the rat by syngeneic islet cell transplantation has been well documented [1,2]. The portal vein has been demonstrated as the most effective site for such transplantation [3], although the peritoneal cavity [4] and spleen [5] have also been used. However, in the case of allogeneic transplants success has been limited, although some prolongation of islet graft survival has been obtained, for example using anti-lymphocyte serum [5, 6], donor specific enhancing serum [7], immunosuppressive drugs [8] or by induction of impaired responsiveness using Bordetella Pertussis and liver extract [9].
Diffusion chambers have been widely used for some years as a means of maintaining the survival and function of the enclosed tissue after transplantation by allowing the passage of essential nutrients, whilst at the same time separating the implanted tissue from the cells of the host which would otherwise be harmful to the implant. This technique has been applied to a variety of tissues including thyroid [10], thymus [11], ovarian tissue [12] and haemopoietic cells [13]. Diffusion chambers constructed of Millipore filters have been used to enclose pancreatic islet implants in studies on hereditary obese mice $[14,15]$, while very transient reduction in plasma glucose was demonstrated in diabetic rats xenografted with piscine islets [16] in Millipore envelopes. Recently Gates \& Lazarus have reported reversal of streptozotocin diabetes in rats by implantation of diffusion chambers containing neonatal rabbit pancreata [17].

In view of these encouraging reports and of their obvious implications in permitting successful allogeneic and xenogeneic transplantation, we have undertaken a detailed study of the functional characteristics of islets transplanted within diffusion chambers using a syngeneic rat transplant model in order to eliminate immunological complications of rejection. The results of these investigations are described below.

\section{Materials and Methods}

\section{Diffusion Chambers}

These were constructed by attaching polycarbonate filters (Biorad) $13 \mathrm{~mm}$ diameter, and of $0.4 \mu \mathrm{m}$ pore size to lucite rings using polyacrylic cement. The lucite rings had a hole drilled in their circumference through which a $1 \mathrm{~cm}$ length of polythene tubing was introduced to allow injection of the islets into the chambers. This tube was sealed after injection of the islets. The pre- 


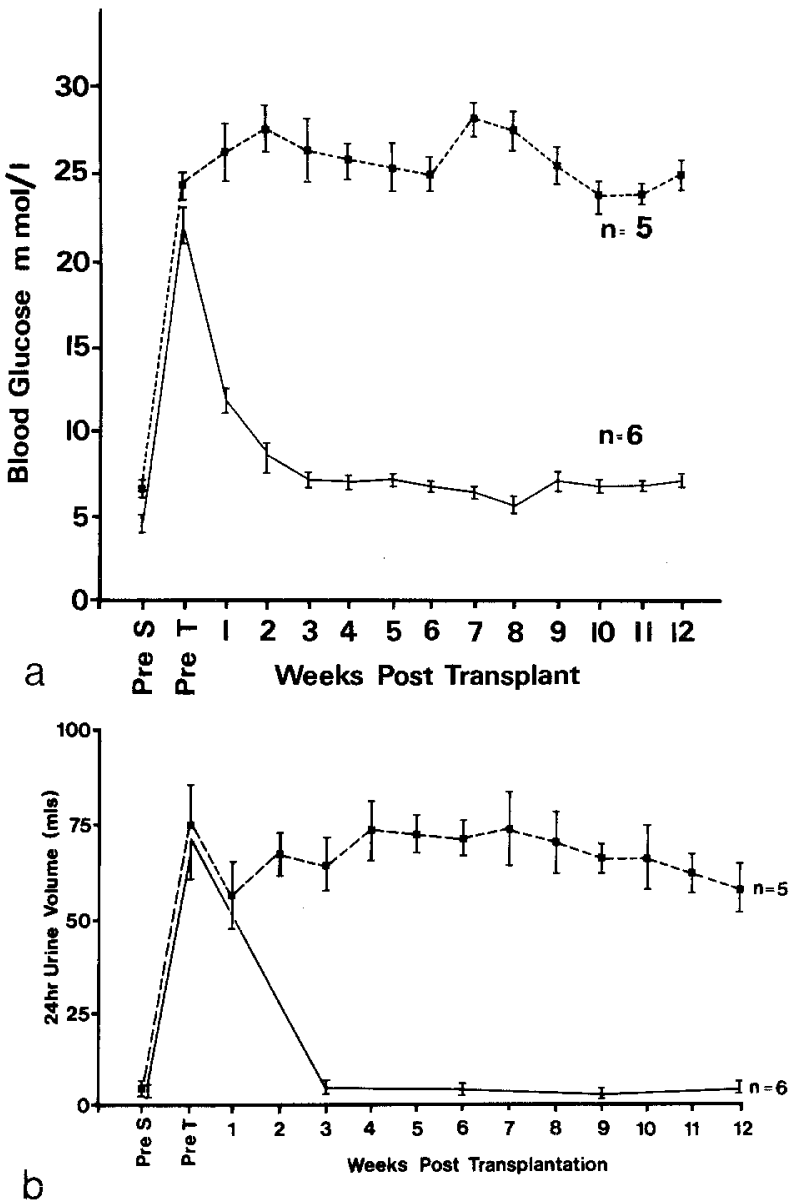

Fig. $1 \mathrm{a}$ and $\mathbf{b}$. Blood glucose concentrations $\mathbf{a}$ and $24 \mathrm{~h}$ urine volumes $\mathbf{b}$ in rats before streptozotocin (Pre S), before transplantation (Pre T) and after transplantation of 1100-1400 islets. - Islets transplanted after enclosure in a diffusion chamber $(\mathrm{n}=5$ animals $) . \longrightarrow$ Islets transplanted directly via portal vein $(\mathrm{n}=6$ animals). Results are given as means \pm SEM

implanted chambers had a 19 gauge cannula introduced into the hole in their circumference and had a rubber bung on the end. When the chamber was implanted into the peritoneal cavity, the cannula was positioned subcutaneously in the rat's flank. The chambers were autoclaved prior to use, and the sterilisation monitored by autoclave tape.

\section{Rats}

These were bred and weaned in the Animal Unit of Charing Cross Hospital Medical School. Inbred female Wistar rats (WAG/Cxms Gth, RT-1u) between $140-180 \mathrm{~g}$ were used as recipients, and donors were pretreated $1-1 \frac{1}{2} \mathrm{~h}$ prior to sacrifice with $4 \%$ pilocarpine hydrochloride intraperitoneally ( $40 \mathrm{mg} / \mathrm{kg}$ body weight) [18]. They were sacrificed by cervical dislocation.

Islets were isolated by a collagenase digestion procedure [19] and picked by hand. A bicarbonate-buffered medium [20] containing $5.5 \mathrm{mmol} / 1$ glucose was used throughout. The time elapsing from removal of the pancreas to transplantation was approximately $2 \mathrm{~h}$ : yields of islets from the pilocarpine-pretreated donors averaged $1100-1400$ per 4 pancreata [18].

\section{Induction of Diabetes}

Diabetes was induced by an IV injection of streptozotocin, $65 \mathrm{mg}$ / $\mathrm{kg}$ body weight in $0.05 \mathrm{~mol} / \mathrm{l}$ sodium citrate with $\mathrm{pH}$ adjusted to 4.5. The animals were considered diabetic only if they had had at least 2 consecutive blood glucose values $>20 \mathrm{mmol} / \mathrm{l}$, and a urine output of $>50 \mathrm{ml} / 24 \mathrm{~h}$ with glycosuria during the month before transplantation.

The animals were maintained on CRM diet (Labsure Animal Foods, Dorset) and water ad lib. They were bled via the orbital sinus under brief ether anaesthesia and nonfasting samples of blood were taken before $11 \mathrm{a}$. $\mathrm{m}$. Post-transplanted blood glucose estimations were performed daily for the first week and then weekly. Blood glucose concentration was estimated by a glucose oxidase method (God-Perid, Boehringer Ltd., Lewes, Sussex). The rats were confined to metabolic cages once a week for measurement of $24 \mathrm{~h}$ urine output, which was also tested for glycosuria (Dextrostix, Ames Co.). Rats were weighed weekly.

\section{Transplantation}

Intraportal Transplants. Under ether anaesthesia the abdomen was opened via a midline incision. The portal vein was identified and cannulated with a 25 gauge bufferfly needle and the islets were injected. Surgical gauze was used for haemostasis and the abdomen closed.

Direct Diffusion Chamber Implants. The isolated islets were suspended in TC 199 culture medium and introduced into the chamber via the tubing on its circumference. After introduction of the islets the tubing was sealed by the application of a sterile clip, and the chamber implanted into the peritoneal cavity of the rat via a midline incision. The chambers were removed 12 weeks after implantation and their insulin content estimated.

Pre-implanted Diffusion Chambers. The abdomen was opened via a midline incision and the chamber implanted into the left iliac fossa. The muscle layer was closed with catgut around the cannula. A subcutaneous pocket was then fashioned in the flank of the animal and the cannula and its covering bung was placed in this pocket. The skin was then closed. At the time of transplantation the chamber was gently aspirated of peritoneal fluid via the bung, and the islets injected into the chamber. The dead space of the cannula would then be flushed with a known volume of TC 199 culture medium. These chambers were used 3, 5, 7, 12 weeks after implantation.

All transplants were given subcutaneous long acting penicillin (15,000 Units/kg body weight) (Duplocillin, Gist-Brocades N. V., Delft, The Netherlands) for $48 \mathrm{~h}$ after the operation.

\section{Permeability and Efficacy of Implanted Chambers}

The ability of the diffusion chambers to allow the passage of insulin was assessed in vivo, and then in vitro. In vivo, diffusion chambers with cannulae were implanted into diabetic rats. Approximately 10 units of bovine serum insulin B.P. (80 U/ml) was injected into the chamber via the cannula, and the dead space of the cannula was flushed through with $0.154 \mathrm{~mol} / \mathrm{l}$ saline. Blood glucose estimations were performed $30,60,80$ and $120 \mathrm{~min}$ after injection of insulin when the chambers had been in situ for at least 6 weeks.

In vitro the diffusion of $\mathrm{I}^{125}$ labelled insulin was determined in newly-constructed chambers, and then again in chambers which had been implanted for at least 2 months. The method has previously been described in detail [21]. 
Membranes of diffusion chambers, which had been allowed to lie in the peritoneal cavity of rats, without islets, for at least 2 months were fixed in 3\% glutaraldehyde and processed for scanning electron microscopy by a critical point drying procedure [22].

\section{Insulin Assay}

Insulin was extracted from some recovered chambers by incubation in acidic ethanol (ethanol: water: conc.HCl; $23.5: 7.0: 0.45$ ) for $72 \mathrm{~h}$ at $4{ }^{\circ} \mathrm{C}$ before dilution of the extracts with $0.1 \mathrm{~mol} / \mathrm{l}$ sodium phosphate buffer, $\mathrm{pH} 7.4$. Alternatively they were incubated for a succession of periods of $30 \mathrm{~min}$ at $37^{\circ} \mathrm{C}$ in bicarbonatebuffered media containing $1 \mathrm{mg} / \mathrm{ml}$ albumin (Armour Pharmaceuticals Eastbourne, Sussex) in conditions noted under Results. The insulin content of extracts and media was subsequently estimated by an immunoassay procedure utilising rat insulin standards and $\mathrm{I}^{125}$ insulin iodinated in our laboratory by the method of Hunter and Greenwood [23]. In this system $50 \%$ displacement of bound $\mathrm{I}^{125}$ insulin was achieved by addition of $2 \mathrm{ng}$ / $\mathrm{ml}$ rat insulin.

\section{Results}

\section{Transplantation Experiments}

In a first series $1100-1400$ freshly isolated islets were enclosed in sterile chambers and implanted directly in the peritoneal cavity of five streptozotocin-diabetic rats. Blood glucose concentrations were monitored daily for the next 7 days, and weekly thereafter for 12 weeks (Fig. 1a). It is clear that there was no significant fall in blood glucose level. In contrast, rats receiving a similar number of islets via the portal vein showed complete normalization of blood glucose within 2 weeks of transplantation (Fig. 1a). Urine volume measurements confirmed the difference in effectiveness of these methods of transplantation (Fig. 1b). After three months the chambers were recovered and opened and their insulin content was estimated. The mean insulin concentration of the content of 5 chambers was $85 \pm 14.3 \mathrm{ng}$ insulin (mean \pm SEM), approximately equivalent to the insulin content of one normal islet [24]. Visual and histological examinations failed to reveal the presence of islet tissue within the chambers.

One reason for the failure of the islets to survive in the chambers could be that preliminary vascularization of the chamber might be necessary. Chambers with attached cannulae were therefore implanted without islets, and were subsequently loaded with $1100-1400$ islets $3-12$ weeks later. In 2 out of 6 of these experiments a rapid and complete lowering of blood glucose (Fig. 2) with concomitant reduction of urine volumes was seen. However, removal of the chambers from these two rats 6 and 7 weeks after the islets were transplanted, did not result in reversion of blood glucose to the previous diabetic levels (Fig. 2).

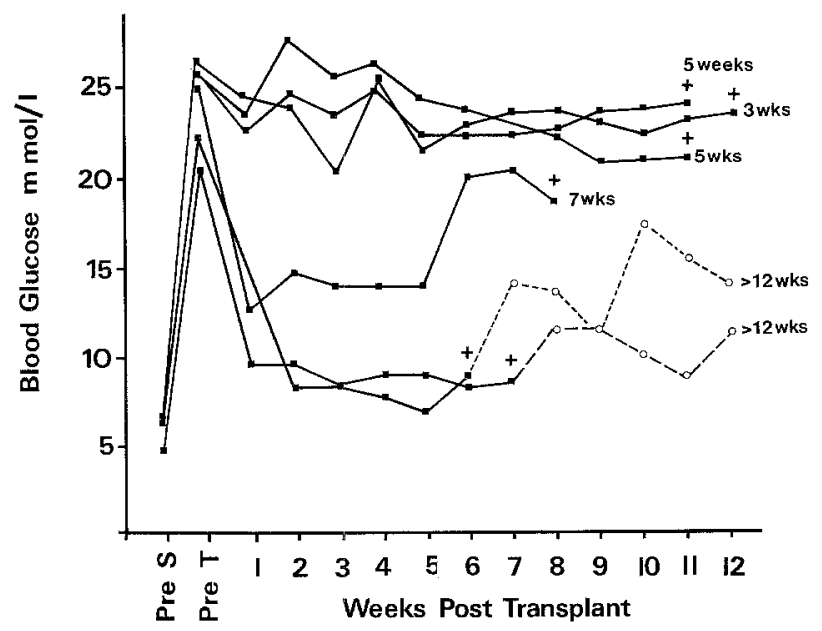

Fig. 2. Blood glucose concentrations of rats which received islets transplanted into a diffusion chamber at the number of weeks shown after implantation of the chamber. Results from individual animals are shown. At the time marked by + , the chambers were removed. Blood glucose levels were monitored in 2 rats after removal of the chamber $(\mathrm{O}----\mathrm{O})$

On close examination the chambers were found to have ruptured, probably during or shortly after the injection of islets with resultant escape of the latter into the peritoneal cavity where they presumably functioned as an intraperitoneal transplant.

Sequential incubation of these recovered and opened chambers, after a pre-incubation period of $30 \mathrm{~min}$ in media containing $5.5 \mathrm{mmol} / 1$ glucose, for successive $30 \mathrm{~min}$ periods in $5.5 \mathrm{mmol} / 1,20 \mathrm{mmol} / 1$ glucose and $20 \mathrm{mmol} / 1$ glucose $+5 \mathrm{mmol} / 1$ theophylline at $37^{\circ} \mathrm{C}$ gave mean rates of insulin release of 11.7, 19.2 and $9.5 \mathrm{ng}$ insulin/30 min respectively. The chambers from the animals in which the transplants appeared ineffective were found to be intact, but to contain no visible islet tissue.

It also proved impossible to recover viable islet tissue with normal secretory characteristics $20 \mathrm{~h}$ after the initial implantation.

\section{Characteristics of the Recovered Membranes}

The degree of fibrosis which occurred around the membranes varied considerably. Fig. $3 \mathrm{a}$ and $3 \mathrm{~b}$ show chambers in situ 12 weeks after implantation. There appeared to be no correlation between the degree of fibrosis and the success of the transplant. The permeability of the membranes was tested by examining the effectiveness of insulin administered via a cannula into the chambers 6 weeks after implantation. Insulin administered in this way was able to lower blood glucose significantly from an initial value of $30.7 \pm 1 \mathrm{mmol} / 1$ to $17.4 \pm 1.7 \mathrm{mmol} / 1$ at one hour 


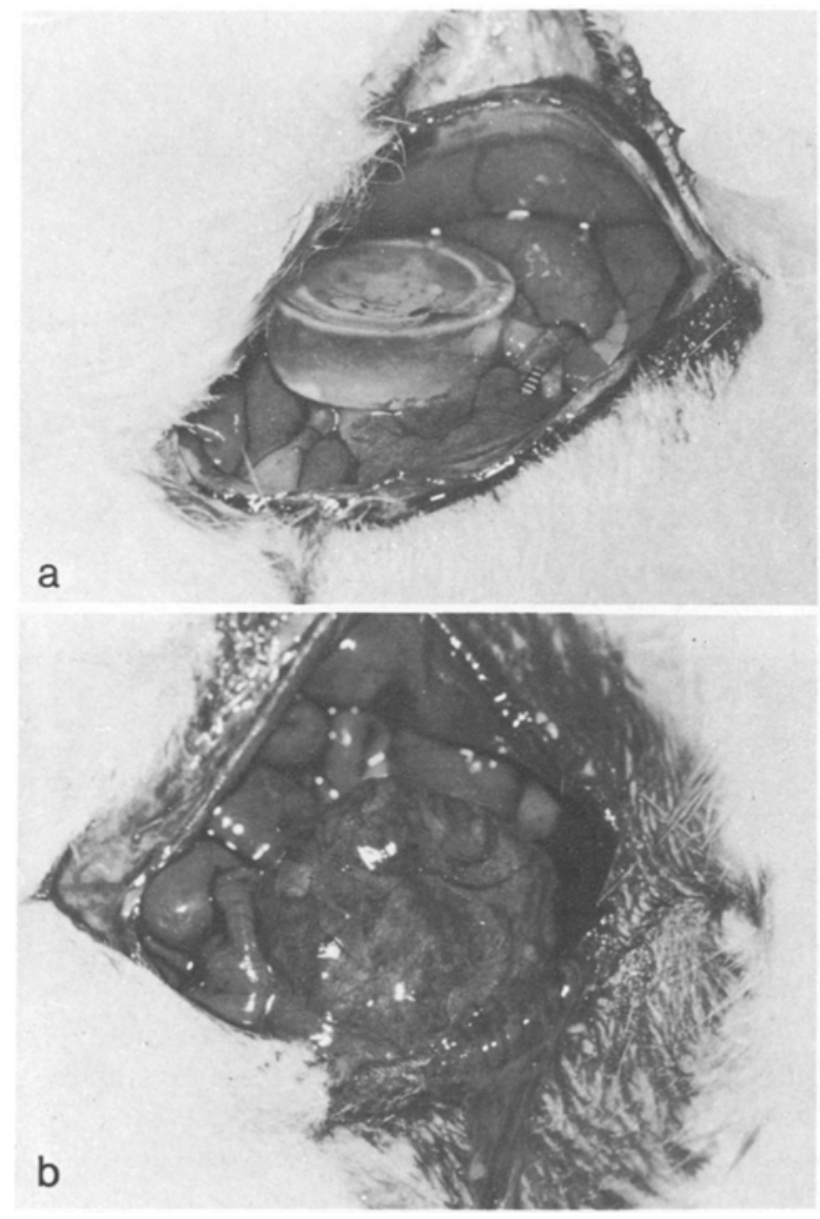

Fig. 3a and b. Photographs of diffusion chambers in situ as seen on first opening the peritoneal cavity 12 weeks after implantation. These show the variation which can occur in the degree of fibrosis. Magnification: $\times 2$

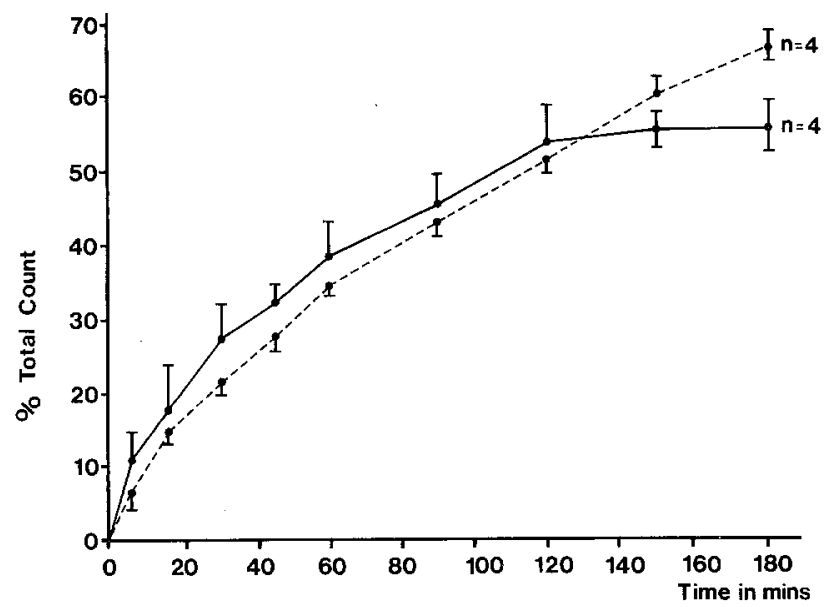

Fig. 4. Diffusion of $\mathrm{I}^{125}$ insulin across the membranes of unimplanted diffusion chambers $-0--1$, and in those which had been removed after 6 weeks - $\longrightarrow$ intraperitoneal implantation. Mean \pm SEM. Percentage of the total radioactivity diffused out of the chamber at each time is shown after injection and $12.6 \mathrm{mmol} / \mathrm{l} 2 \mathrm{~h}$ after injection. Comparable experiments using $\mathrm{I}^{125}$ insulin were performed in vitro on chambers recovered 6-8 weeks after implantation. There was no difference in the rate of $\mathrm{I}^{125}$ insulin diffusion between unimplanted chambers and those recovered after this period (Fig. 4).

Scanning electron microscopy of the inner surface of chambers recovered 6-8 weeks after implantation showed the pores still to be patent with fragments of some material too small to be cells overlying the surface. In rare cases (one or two areas of each membrane), a relatively large mass of cells, presumably residual islet tissue since no other cells could have penetrated, was found on the surface of the membranes.

\section{Discussion}

A preliminary assessment of a selection of membranes with respect to the diffusion of glucose (the physiological secretagogue) and insulin (the main secretory product) in vitro demonstrated that membranes composed of polycarbonate (Nucleopore, Biorad), polypropylene or cellulose triacetate allow a much more rapid diffusion of insulin than other membranes tested including cellulose nitrate (Millipore) [21]. The chemical composition of the membrane did not affect the diffusion of glucose. We therefore chose to use diffusion chambers constructed with polycarbonate membranes to give optimal insulin diffusion, and to use syngeneic islets in order to avoid any possible immunological complications.

It is clear from the above results that even under these optimal conditions, there are severe problems in obtaining reversal of diabetes by transplantation of islets enclosed within polycarbonate chambers to syngeneic streptozotocin-treated recipients. It seems unlikely that this failure results from the use of an inadequate number or quality of islets, but rather from the inability of the islets to survive within chambers which have been implanted in the peritoneal cavity. The inability to recover viable tissue cannot be due solely to fibrosis reducing the permeability of the boxes, because it occurred apparently equally both in freshly implanted chambers, and those which had been implanted 3-12 weeks previously. It was noted that the amount of vascular reaction or fibrosis around the chambers could be minimised by adequate sterilisation of the chambers and strict asepsis. Under these conditions the reaction to the empty chamber is limited to the formation of a fibrous capsule, remarkably avascular, and histologically comprising fibroblasts $10-15$ cells thick. A more severe reaction was noted around chambers containing 
islets, emphasising the importance of maintaining sterility while isolating the islets in this type of experiment. Preliminary experiments, where this was not appreciated, often resulted in abscess formation around the chamber. It seems likely that islet viability in diffusion chambers must depend on factors other than establishment of an adequate blood supply to the chamber membranes. It is unlikely that toxicity of the chambers is a factor since polycarbonate membranes have been used for culture of several types of cells [25].

We have therefore found it impossible to devise a reproducible model for syngeneic islet transplantation by encapsulation of islets within commercially available semipermeable membranes. For the time being the use of such chambers for islet transplantation may be restricted to the specific situations in which its efficiency has been demonstrated by others (14-17), although it is notable that there has recently been some discussion as to the reproducibility of some of the results which have been reported [26].

Even in those circumstances in which tissue can be maintained successfully within semi-permeable chambers, problems of the slow diffusion time of glucose and of insulin across the membrane [21] suggest that they will not provide an effective mechanism of blood glucose regulation on a minute-to-minute basis. Future advances in this potentially useful transplantation model must await the development of membranes whose characteristics are more suitable for this specific purpose.

Acknowledgements. We thank Professor A. J. Harding Rains for advice and encouragment. Financial assistance from the Medical Research Council, British Diabetic Association and the North West Thames Regional Health Authority is gratefully acknowledged. NAT is a Governors Trustees Research Fellow of Charing Cross Hospital.

\section{References}

1. Matas A J, Sutherland DER, Najarian JS (1976) Current status of islet and pancreas transplantation in diabetes. Diabetes 25: 785-798

2. Karl R C, Scharp DW, Ballinger WF, Lacy P E (1977) Transplantation of insulin secreting tissues. Gut 18: 1062-1072

3. Kemp C B, Knight MJ, Scharp D W, Ballinger W F, Lacy PE (1973) Effect on transplantation site on the results of pancreatic islet isografts in diabetic rats. Diabetologia 9: 486-491

4. Ballinger WF, Lacy PE (1972) Transplantation of intact pancreatic islets in rats. Surgery 72: $175-186$

5. Finch DRA, Wise PH, Morris PJ (1977) Successful intrasplenic transplantation of syngeneic and allogeneic isolated pancreatic islets. Diabetologia 13: 195-199

6. Finch DRA, Morris PJ (1977) Failure to demonstrate a synergistic effect between enhancing serum and ALS in recipients of pancreatic islet allografts. Transplantation 23: 386-388

7. Finch D RA, Morris PJ (1976) Passive enhancement of isolated pancreatic allografts. Transplantation 22: 508-512
8. Finch DRA, Morris P J (1977) The effect of increasing islet numbers on survival of pancreatic islet allografts in immunosuppressed diabetic rats. Transplantation 23: 104-106

9. Nelken D, Morse SI, Beyer M M, Friedman E A (1976) Prolonged survival of allotransplanted islets of Langerhans cells in the rat. Transplantation 22: 74-75

10. Potter JF, Haverback CF (1960) Homotransplantation of endocrine tissues in a diffusion chamber. Ann Surg 151: 460-464

11. Levey R H, Trainin N, Law L W (1963) Evidence for function of thymic tissue in diffusion chambers implanted in neonatally thymectomised mice. J Natl Cancer Inst 31: 199-206

12. Sturgis $\mathrm{SH}$, Castellanos $\mathrm{H}$ (1957) Functional survival of ovarian homografts within Millipore filter chambers in the castrated rat. Proc Soc Exp Biol Med 94: 569-572

13. Carsten A L, Chanana AD, Chikappa G, Cronkite EP, Öhl S (1975) An improved diffusion chamber for culture of haemopoietic cells. Proc Soc Exp Biol Med 150: 107-109

14. Strautz RL (1970) Studies on hereditary-obese mice (obob) after implantation of pancreatic islets in Millipore filter capsules. Diabetologia 6: 306-312

15. Gates R J, Hunt MI, Smith R, Lazarus N R (1972) Return to normal of blood glucose, plasma insulin, and weight gain in New Zealand obese mice after implantation of islets of Langerhans. Lancet II: 567-570

16. Weber C, Weil R, McIntosh R, Hogle H, Warden G, Reemtsma K (1975) Xenotransplantation of piscine islets into hyperglycaemic rats. Surgery 77: 208-215

17. Gates RJ, Lazarus NR (1977) Reversal of streptozotocininduced diabetes in rats by intraperitoneal implantation of encapsulated neonatal rabbit pancreatic tissue. Lancet II: $1257-1259$

18. Vrbova H, Theodorou NA, Tyhurst M, Howell SL (1979) Transplantation of islets of Langerhans from pilocarpine pretreated rats - a method of enhancing yield. Transplantation 28: $433-4.35$

19. Howell S L, Taylor KW (1966) Effect of glucose on incorporation of $\left({ }^{3} \mathrm{H}\right)$ leucine into insulin in isolated rabbit islets of Langerhans. Biochim Biophys Acta 130: 519-521

20. Gey GO, Gey MK (1936) Maintenance of normal human cells and tumour cells in tissue culture. Am J Cancer 27: 45-76

21. Theodorou NA, Howell S L (1979) An assessment of diffusion chambers for use in pancreatic islet transplantation. Transplantation 27: 350-352

22. Anderson TF (1951) Techniques for the preservation of three-dimensional structure in preparing specimens for the electron microscope. Trans NY Acad Sci 13: 130-136

23. Hunter WM, Greenwood, FC (1962) The preparation of iodine-131 labelled human growth hormone of high specific activity. Nature 194: 495-496

24. Ammon HPT, Steinke J (1972) 6-Aminonicotinamide as a diabetogenic agent. Diabetes 21: 143-148

25. Nopanitaya W, Charlton R K, Turchin RL, Grisham JW (1977) Ultrastructure of cells cultured on polycarbonate membranes. Stain Technol 52: 143-149

26. Garvey JF, Morris PJ, Finch DRA, Millard PR, Poole M (1979) Experimental pancreas transplantation. Lancet I: 971-972

Received: July 19, 1979,

and in revised form: November 2, 1979

Dr. S. L. Howell

Department of Biochemistry

Charing Cross Hospital Medical School

Fulham Palace Road

Hammersmith

London W6 8RF

England 